\title{
Rentgenski snimak stopala, petne kosti i skočnog zgloba - paralelni prikaz prema indikaciji
}

\section{Dušica Ranđelović, Viši Rtg tehničar CVMU Beograd, VMC Novi Beograd}

Sažetak: Cilj ovog izlaganja je da se prikazom radiografske anatomije kostiju nožja obrazloži značaj pravilne indikacije i precizno određene uputne dijagnoze na osnovu kojih se načini retgenski snimak (Rgt grafija) na tačnoj lokaciji degenerativne, traumatske ili deformativne promene: stopala, skočnog zgloba i petne kosti. Precizna uputna dijagnoza je veoma važna da bi se odredila pravilna pozicija pacijenta tokom rentgenskog snimanja odnosno učinili vidljivim baš određeni delovi pojedinačnih kostiju a u saglasnosti sa indikacijom. Rad sadrži elemente vezane za tehničke uslove za izradu radiografije. Naročito važan je objekat snimanja i radiografska pozicija pacijenta kod grafisanja kostiju nožja.

Uporednim prikazom sa ostalim Rentgenskim grafijama načinjenim u Rtg Kabinetu VMC Novi Beograd izneti su statistički podaci za 2013-u godinu i grafije kostiju nožja određenih patoloških stanja.

U završnom delu rada opisan je značaj promena na stopalima vezanih za starenje; uticaj potpetica na zdravlje tj. posledice nošenja istih i promene na stopalima koje dovode do poremećaja statike tela, ugrožavanja i deformacije kolena, kukova i kičme.

Ključne reči: Indikacija, pozicija, potpetica, starenje, Rrg grafija stopala, skočnog zgloba i petne kosti.

Abstract: This paper's aim is to show, by using radiographic foot bones anatomy, how it is important to have well established indication and very precise diagnosis on which $x$-ray images are to be taken of exact location where degenerative, traumatic or deformative changes show up in foot, heel bone and ankle joint. Precise diagnosis is important in order to properly position a patient during $x$-ray but furthermore to make specific bones visible in accordance with indication.

This paper contains technical elements about x-ray imaging. It specifically examines radiographic position of a patient while making $x$ ray image of foot bones.

$X$-ray imaging of foot bones in various pathological states is compared with other $x$-ray images made in VMC Novi Beograd. Statistical overview is given for the year 2013.

Change in foot bones that come with ageing is explained in conclusion; impact of wearing heels on health and changes on feet that lead to imbalanced static of the body, damaged and deformed knees, hips and spine.

Keywords: Indication, position, heels, ageing, $x$-ray of foot, heel bone and ankle joint.

UVOD

$\mathrm{O}$ vim izlaganjem dat je opis koštanih struktura nožja: stopala, petne kosti i skočnog zgloba odnosno tačna lokacija degenerativne, traumatske i deformativne promene. Na osnovu indikacije i precizno određene uputne dijagnoze i pravilnim pozicioniranjem dobija se Rg grafija na kojoj se može videti i opisati promena.

U 2013-oj godini primili smo oko 260 pacijenata sa potrebom snimanja kostiju nožja:

- 114 stopala i prstiju stopala, oko 50 petnih kostiju i oko 94 skočnih zglobova - procentualno to je 7,5 \% od svih grafija a u odnosu na druge kosti $11 \%$.

- To nisu najčěšće snimane kosti, tj snimljeno je 465 kolena, 387 L/S kičmi, 258 K/K, 358 C-kičmi, rame 190, kosti ruke 270 (glave 85 , stomaka 22, grudi 126 a pluća 960 )...., uglavnom su poslati sa uputnim Dg: gonartrosis, Sy lumbalae, coxarthrosis...a manje je bilo usled povređivanja i - što govori o starosnoj dobi pacijenata.

C $\begin{aligned} & \text { Putovanje od hiljadu milja } \\ & \text { počinje jednim korakom }\end{aligned}$

Lao Ce

\section{TEHNIČKI USLOVI ZA RADIOGRAFIJU}

Faktori koji utiču na kvalitet radiografije:

- prodornost rendgenskih zrakova (napon rendgenske cevi)

- intenzitet rendgenskih zrakova (struja rendgenske cevi),

- trajanje ozračivanja (ekspozicija).

- veličina izvora rendgenskih zarakova - veličina fokusa rtg cevi - rastojanje između fokusa randgenske cevi i filma (FFD)

- rasipanje rendgenskih zrakova

- objekt snimanja (pozicija)

- rendgenski film i njegova tehnička obrada

- pojačivački elementi (fluorescentne folije)

\section{RADIOGRAFSKA POZICIJA}

- međusobni odnos tri faktora: položaj bolesnika, pravac centralnog zraka i položaj kasete sa filmom

- To su osnovni radiološki elementi za svako radiološko snimanje. Pravilnim pozicioniranjem snimljeni objekt treba što jasnije da se istakne, da sadrži bogatstvo radiloških detalja, što manje superponiranja organa i da je što manje deformisan. 


\section{INDIKACIJE ZA RTG GRAFIJE NOŽJA}

\section{POVREDE:}

- Distorzije (uganuća) kada može doći do lomljenja lateralnogmaleolusa ili još jačom silom do trimaleolarnih preloma.

- Luxacije (iščašenja) može doći do ligamentarnih povreda. Upredelu skočnog zgloba i metatarsofalangealnih zglobova su uglavnom udružene sa prelomima maleolusa.

- Prelomi (fracture) skočnog zgloba, talusa - nastaju padom sa visine na petu pri plantarno flektiranom zglobu.

- Prelomi tarzalnih, metatarzalnih kostiju i falangi nastaju direktnim delovanjem sile.

\section{UROĐENE DEFORMACIJE I STEČENA OBOLJENJA:}

- ravno stopalo, čukalj (hallux valgus), povijen, čekićast prst, Calcar -spina-calcanei;

- Artroze, giht, osteomyelitis, otok, bol; reumatska i maligna oboljenja

\section{PRIPREMA PACIJENTA ZA RTG EKSTREMITETA}

- protokolarno evidentiranje

- pripremiti materijal, aparat

- osloboditi odeću i obuću koja bi mogla dati nepoželjnu senku - gonade pokriti zaštitnom keceljom

- suziti blendu na veličinu kasete

- pri snimanju dece, dati uputstva pratiocu

\section{RADIOGRAM KOSTIJU STOPALA (DORSO-PLANTARNI)}

\section{Položaj pacijenta:}

a) Pacijent leži na leđima (ili sedi). Noga je savijena u kolenu a stopalo naleže na sto odnosno kasetu.

b) Pacijent sedi ili leži. Noga je savijena, a snimano stopalo iskošeno je pod uglom 450 pomoću strme ravni

Pravac centralnog zraka:

a) Iskošen je i pada na sredinu gornje povrsine stopala odnosno kasete

b) Iskošen je kaudalno, ali tako da pada na sredinu kasete pod pravim uglom

Ako se snimaju prsti stopala i najčešće, centralni zrak pada pod pravim uglom na sredinu kasete odnosno stopala.

Materijal i opis: prilagoditi veličinu filma; Kaseta prelazi ivice prstiju za $3 \mathrm{~cm}$. Uzdužna osa stopala poklapa se sa sredinom kasete. Snimanje sa folijama; bez rešetke; tubus široki; FFD 80$100 \mathrm{~cm}$.

\section{POLUKOSI, PROFILNI SNIMAK STOPALA I PRSTIJU}

Kosi snimci stopala (foot oblique) se rade u lateralnoj ili medijalnoj projekciji i u zavisnosti od toga snimana noga se okreće, zaklapajući ugao od 450 u odnosu na kasetu - plantarnom stranom odnosno dorzumom.

Profilni snimak: Pacijent je okrenut na bok strane koja se snima, noge su savijene u kolenima. Snimano stopalo leži spoljnom stranom na kaseti. CZ je pod pravim uglom na bazu treće metatarzalne kosti.

Radiogram prstiju stopala je dorzo-plantarni i kosi. CZ je pod uglom od 900 i uperen na proksimalnu falangu III prsta. Prsti u kosoj projekciji se snimaju tako što je stopalo iskošeno i oslonjeno na kasetu spoljnom ivicom odnosno dorzalnom stranom, osim palca. Snimani sedi odnosno leži na stomaku. Za ciljana snimanja prstiju pojedinačno koriste se tubusi.

\section{MODIFIKACIJE PREMA INDIKACIJI}

- uporedni snimci oba stopala, petne kosti

- snimanje u stojećem stavu pod opterećenjem

- dopunske grafije korišćenjem klinastih podložaka sa kosinom 15-20 stepeni

- polukosi, kosi i ciljani snimci, uglovi 45o, 30o, 20o

- snimanje kroz gips i pacijenata sa ograničenom pokretljivošću

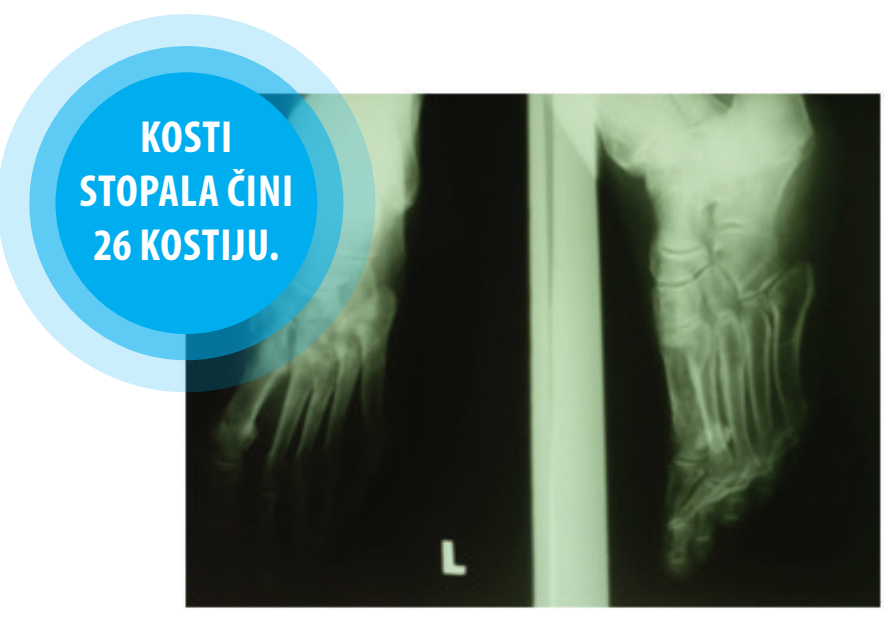

To su kratke kosti : 7 nožja (tarsus), 5 donožja (metatarsus) i 14 prstiju (phalanges digitorum).

Najveća je petna kost- Calcaneus. Njome se oslanjamo kad hodamo.

Iznad nje je skočna kost - Talus a ispred je čunasta kost- os naviculare. U polju sa njom se nalazi os cuboideum-kockasta kost. Ispred se nalaze tri umetnute klinaste kosti - os cuneiforme mediale, intermedium i laterale.

Strana stopala na koju stajemo zove se plantarna a gornja je dorsum pedis. U stopalu palac se naziva hallux. Stopalo ima medjalnu i lateralnu stranu, na kojoj je mali prst. Između kosti tarsusa nalaze se metatarzalne kosti.

\section{SKOČNI ZGLOB}
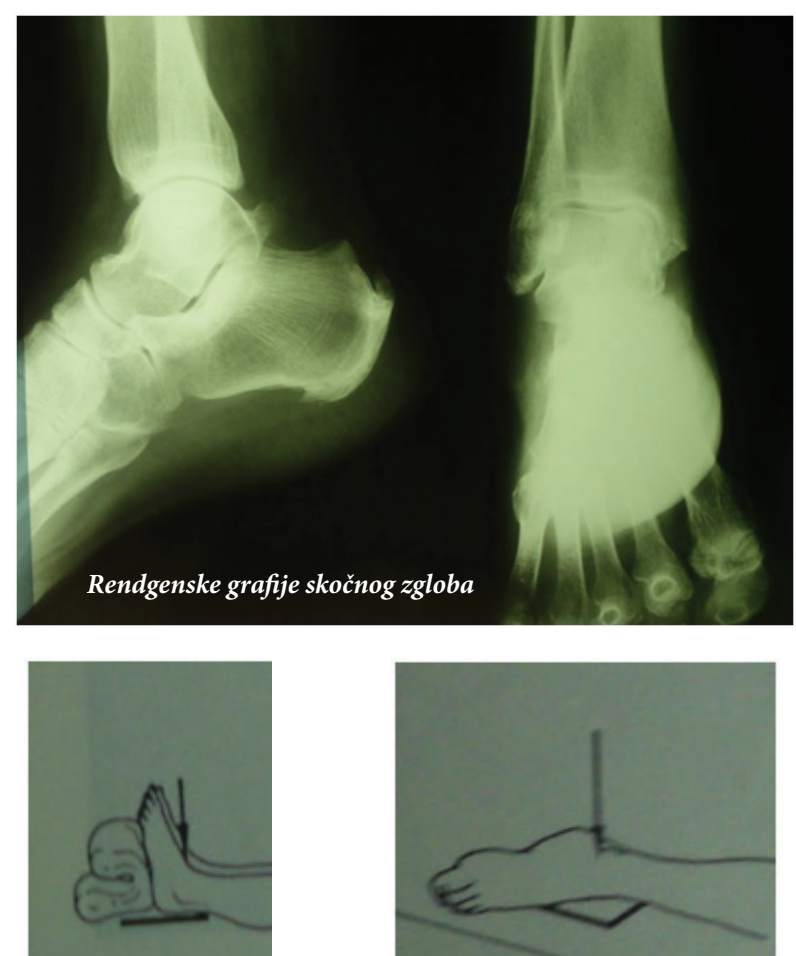
Skočna kost se spaja sa dve potkolene kosti, tibijom i fibulom gradeći skočnu površinu-Trohlea talli. Ona je konveksna. Zglobljava se sa oba maleolusa koji grade zglob. Talus se zglobljava sa petnom kosti-calcaneus i gradi zglob -articulacio subtarsus.

ATC anterio-posterior: Snimana noga je opružena,stopalo bez fleksije(ili plantarno flektirano), blago medijalno ukošeno. Centralni zrak usmeren na zglobnu pukotinu.

Uporedni snimak oba skočna zgloba.

Profini snimak skočnog zgloba

Kosi snimci skočnog zgloba se rade uvek u medijalnoj i lateralnoj rotaciji za 450 .

\section{PETNA KOST - CALCANEUS}

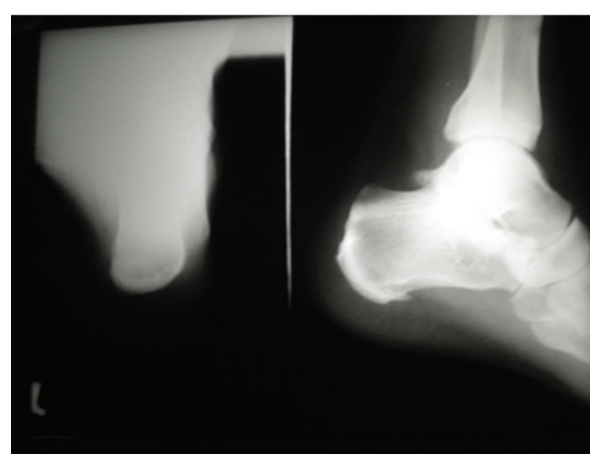

Snimak profila petne kosti radi se kao i profil skočnog zloba a CZ je pod pravim uglom po sredini calcaneusa na medijalnoj strani pete.

Aksijalni snimak calcaneusa (i uporedni na dva načina) ležeći na leđima, stopalo flektiranodorzalno, CZ ukošen 40o na sredinu pete(a).Ili, retko usedećem položaju savijenih nogu da se spoje petne kosti. Aksijalni snimak u „Startnom položaju“-stojeći nagnut položaj na strmoj ravni sa tanjim delom pod prstima.CZ pod pravim uglom ili kranijalno ukošen za 10o.

CC

Bio sam besan što nemam dobre cipele, a onda sam otišao na trg i tamo sreo čoveka bez nogu. Kineska poslovica

\section{ZANIMLIVO...}

POTPETICA ILI ŠTIKLA je deo obuće koji podiže petu, a kad su izdignuti i prsti i peta to je platforma. - nastala u XV veku, početkom 1500 godine i bila visine $3 \mathrm{~cm}$ - ,jahačeva peta“.

- krajem XVI je svakodnevna muška obuća na dvorovima, visine $6-9 \mathrm{~cm}$

1533 godine,napravljene su drvene cipele sa platformom - šopine, za groficu Katarinu de Miči

nakon Francuske revolucije, odbačene su kao arikrostokratski simbol statusa i bogatstva

vraćene u žensku modu sredinom XIX veka i nakon 60tih i 70-tih god XX potisnula ih je ravna cipela

\section{POTPETICA I ZDRAVLJE}

Nošenje štikli može da izazove širok spektar zdravstvenih problema: od prostog bola u stopalima, grčeva i skraćenja mišića, uraslih noktiju do ozbiljnijih, poput degeneracije zglobova i osteoartritisa.

Ortopedi i neurohirurzi su radili studije i rezultati dovode u vezu probleme sa kičmom, naprimer, skolioza, sa dugotrajnim hodanjem sa visokim potpeticama. Telesna masa se isključivo oslanja na prste te nije ravnomerno raspoređena preko celog tabana.

\section{ŠALJIVO (ILI NE) - ZA RAZMIŠLJANJE...}

- Upozorenja ženama od opasnosti visoke štikle nemaju efekta.
- Formulom, žene same mogu da odrede koja je visina štikle odgovarajuća za njih i koja neće biti pogubna za njihove noge.

Dakle unesite svoje parametre:

$$
H=Q^{*}\left(12+\left(3^{*} S / 8\right)\right)
$$

$\mathrm{H}$ je visina štikle, $\mathrm{S}$ broj cipela koji nosite. $\mathrm{Q}$ je sociološki faktor za čije izračunavanje će vam trebati nova formula, malo komplikovanija od prethodne:

$$
Q=\left(P^{\star} L^{\star}(Y+9)\right) /\left((T+1)^{\star}(A+1)^{\star}(Y+10)^{\star}(L+20)\right)
$$

P - vervatnoća da ćete zahvaljujući cipelama privući pažnju suprotnog pola,

L - cena cipela (u funtama),

$\mathbf{T}$ - je vreme koje je prošlo od kada su cipele bile na vrhuncu popularnosti u modnoj industriji (nula znači da su sada hit!),

A - koliko ćete jedinica alkohola konzumirati dok ih budete nosili,

Y - je vaše iskustvo u nošenju štikli izraženo u godinama.

\section{Moda i profesija}

Kako postoje društvene norme za ponašanje, tako postoje i norme koje nalažu kada se i koje cipele nose i da li priliče situaciji. Nepisano pravilo je da žene na radnom mestu nebi trebalo da nose cipele sa potpeticom višom od $2 \mathrm{~cm}$ jer bi delovale neprofesionalno.

\section{STOPALA I STARENJE}

Stopala postaju duža i šire se starenjem, jer tetive i ligamenti koji povezuju sitne kosti gube elastičnost. Zglobovi postaju manje elastični pa se prsti šire, a stopalo spušta.

Nakon 40. godine broj obuće možete povećati i za jedan broj. Nosite zaštitne jastučiće i što češće nosite dobar par patika za trčanje.

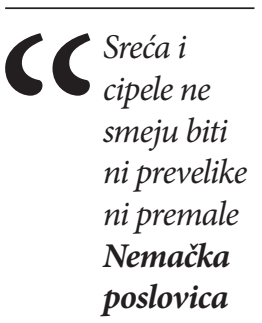

\section{UMESTO ZAKLJUČKA}

Rentgenska grafija se radi na osnovu precizno određene lokacije, indikacije i pravilne uputne dijagnoze. Samo tako se i dobija ispravan radiogram i izbegava greška i maskiranje patologije. Često je potrebno uraditi više različitih grafija i ciljanih projekcija: - Grafijom stopala se ne može prikazati petna kost niti skočni zglob u pravilnoj projekciji.

- Grafija profila skočnog zgloba i profila petne kosti je poziciono identična, prikazuje iste strukture ali je $\mathrm{CZ}$ različito usmeren.

\section{PORUKA:}

Veoma je važno održavanje, nega i pravovremena dijagnostika na stopalima. Promene na stopalima dovode do poremećaja statike tela; ugrožavaju i deformišu kolena, kukove i kičmu.

\section{HVALA, ŽELIM VAM DUGE STAZE!}

\section{Literatura}

1. Anatomija donjeg ekstremiteta: Stefanović N., Antić S.,Pavlović S.- Niš 2002 2. Atlas rendgenske anatomije: W. Firbas, CJ. Herold, W. Schima, 7 izdanje, Medicinska naklada, 2010. godine

3. Praktikum iz kliničke radiogije za studente medicine: Bošnjaković P.Niš, Medicinski fakultet Univerziteta 2007

4. Radiologija - udžbenik za studente medicine i stomatologije: I. Lukač. D Šušćević i saradnici, Stylos, Novi Sad 2000. godine

5. Vikipedija, Potpetica

6. Protokol Rtg Kabineta VMC Novi Beograd za 2013. godinu 